\title{
ERRATUM \\ DIRICHLET PROBLEM ASSOCIATED TO DIVERGENCE FORM PARABOLIC EQUATIONS
}

[Communications in Contemporary Mathematics, Vol. 6. No. 3 (2004) 377-393]

\author{
MARIA ALESSANDRA RAGUSA \\ Dipartimento di Matematica e Informatica, Università di Catania, \\ Viale Andrea Doria 6, 95125 Catania, Italy \\ maragusa@dmi.unict.it
}

There are some type errors in this paper. Their corrections are listed below:

- Page 377, line 4 of the text: The cylinder is $Q_{T}=\Omega \times(-T, 0)$ instead of $Q_{T}=\Omega \times(0, T)$

- Page 379, Definition 2.5(2): The power of $r$ is $-(n+2)$ instead of $-(n+1)$;

- Page 380, Definition 2.8: In formula (2.1) of the fundamental solution $\Gamma\left(x_{0}, \xi\right)$, $t$ should be replaced by $(t-T)$ at all 4 places. 